\title{
Cirurgia periodontal para aumento de coroa clínica
}

\author{
Periodontal surgery for clinical crown augmentation \\ Cirugía periodontal para el aumento clínico de coronas
}

Recebido: 01/12/2021 | Revisado: 06/12/2021 | Aceito: 06/12/2021 | Publicado: 14/12/2021

\author{
Amanda Lima de Araújo \\ ORCID: https://orcid.org/0000-0002-5158-411X \\ Centro Universitário Fametro, Brasil \\ E-mail: amandalima035@hotmail.com \\ Thalia Moreira de Souza \\ ORCID: https://orcid.org/0000-0001-8428-7798 \\ Centro Universitário Fametro, Brasil \\ E-mail: Thaliastone21@gmail.com \\ Juliana Lopes de Sá \\ ORCID: https://orcid.org/0000-0002-1927-2191 \\ Centro Universitário Fametro, Brasil \\ E-mail: juliana.lopes@ fametro.edu.br
}

\begin{abstract}
Resumo
Introdução: No início em 1912, a gengivectomia era tratamento para reduzir bolsas periodontais supra ósseas e remoção de hiperplasias gengivais, atualmente é uns dos procedimentos mais procurados para a correção de sorriso. A gengivoplastia foi sugerida por Goldman em 1950, ficar claro, portanto, que tanto a gengivectomia e a gengivoplastia se pautam pela mesma sequência técnica, ambas são uma cirurgia ressectiva estética visando melhorar o restabelecimento fisiológico do espaço biológico. Metodologia: Trata-se de uma pesquisa de caráter descritivo. Resultados e Discussões: Segundo a literatura, em 1979 foi definida a gengivectomia, como uma excisão de tecido mole da bolsa periodontal patológica. Widmam (1918) também chamou de "retalho original de widmam" onde para estabelecer uma nova fisiologia para o osso alveolar, o autor descreveu a técnica de retalho para eliminar a bolsa periodontal. Kronfeld (1935) concluiu que na gengivectomia não poderia expor o tecido ósseo, sendo esse procedimento indicado para remover o tecido gengival hiperplásico, podendo também remover a gengiva inserida, marginal e papilar (Penteado, 2015). Considerações Finais: Conclui-se que diante do exposto, a gengivoplastia é similar a gengivectomia, porém, com diferenças que na primeira citada, o objetivo seria que a gengiva se torne mais estética na ausência de patologias, já na gengivectomia, seria para excisão da gengiva com a patologia.
\end{abstract}

Palavras-chave: Gengivectomia; Gengivoplastia; Estética.

\begin{abstract}
Introduction: Beginning in 1912, a treatment from the gingivectomy era to reduce supraosseous periodontal pockets and removal of gingival hyperplasia is currently one of the most sought after procedures for smile correction. Gingivoplasty was suggested by Goldman in 1950, making it clear, therefore, that both gingivectomy and gingivoplasty are guided by the same technical sequence, both are an aesthetic resective surgery improving the physiological reestablishment of the biological space. Methodology: This is a descriptive research. Results and Discussion: According to the literature, in 1979, gingivectomy was defined as an excision of soft tissue from the pathological periodontal pocket. Widmam (1918) also called it the "original widmam flap" where to establish a new physiology for the alveolar bone, the author learned the flap technique to eliminate periodontal pocket. Kronfeld (1935) concluded that in gingivectomy it could not expose the bone tissue, and this procedure is indicated to remove the hyperplastic gingival tissue, being also able to remove the inserted, marginal and papillary gingiva (Penteado, 2015). Final Considerations: It is concluded that, given the above, gingivoplasty is similar to gingivectomy, however, with differences that in the first mentioned, the objective would be that the gingiva becomes more aesthetic in the absence of pathologies, whereas in gingivectomy, it would be for excision of the gums with the pathology.
\end{abstract}

Keywords: Gingivectomy; Gingivoplasty; Aesthetics.

\section{Resumen}

Introducción: A partir de 1912, un tratamiento de la era de la gingivectomía para reducir las bolsas periodontales supraóseas y la eliminación de la hiperplasia gingival es actualmente uno de los procedimientos más buscados para la corrección de la sonrisa. La gingivoplastia fue sugerida por Goldman en 1950, dejando claro, por tanto, que tanto la gingivectomía como la gingivoplastia están guiadas por la misma secuencia técnica, siendo ambas una cirugía estética resectiva mejorando el restablecimiento fisiológico del espacio biológico. Metodología: Se trata de una investigación descriptiva. Resultados y Discusión: Según la literatura, en 1979, la gingivectomía se definió como la escisión de tejido blando de la bolsa periodontal patológica. Widmam (1918) también lo llamó el "colgajo widmam original" 
donde para establecer una nueva fisiología para el hueso alveolar, el autor aprendió la técnica del colgajo para eliminar la bolsa periodontal. Kronfeld (1935) concluyó que en la gingivectomía no se podía exponer el tejido óseo, y este procedimiento está indicado para extirpar el tejido gingival hiperplásico, pudiendo extirpar también la encía insertada, marginal y papilar (Penteado, 2015). Consideraciones finales: Se concluye que, dado lo anterior, la gingivoplastia es similar a la gingivectomía, sin embargo, con diferencias que en la primera mencionada, el objetivo sería que la encía se vuelva más estética en ausencia de patologías, mientras que en la gingivectomía, sería Ser para la escisión de las encías con la patología.

Palabras clave: Gingivectomía; Gingivoplastia; Estética.

\section{Introdução}

O sorriso não se baseia somente de forma padrão envolvendo cor, tamanhos e formas, o sorriso também é saúde e indica a presença de tecidos periodontais sadio. A harmonia do sorriso é um ponto onde deve ser avaliado, onde influenciará diretamente na escolha do tratamento (Michael \& Hessam, 2001; Lipska, 2015).

Dutra, (2011) afirma que a estética depende dos dentes, lábios e gengiva, porém, atualmente pacientes de todas as idades e gêneros procuram as clínicas odontológicas em busca de sorrisos perfeitos. Há relatos que o paciente chega à clínica com queixa de dentes pequenos e muita exposição gengival, sendo mais comum na arcada superior com maior concentração nos dentes anteriores. Assim, o sorriso gengival é identificado quando, ao sorrir, o paciente exibe tecido gengival cerca de $3 \mathrm{~mm}$ da margem labial até a linha do lábio superior. O autor ainda afirma que existem técnicas cirúrgicas para remoção desse excesso, favorecendo a estética e removendo a insatisfação do paciente. Como por exemplo, a cirurgia de aumento de coroa clínica é recomendada para pacientes que apresentam excesso gengival, relacionada a patologia ou não.

A causa do excesso gengival é multifatorial. Cita-se o uso de medicamentos que causam hiperplasia gengival, presença de patologias de tecidos moles, problemas sistêmicos, como por exemplo, a diabetes, fatores genéticos, acúmulo de placa bacteriana e uso de aparelho ortodôntico. Também pode surgir no período gestacional, devido à alteração hormonal das grávidas (Carvalho, 2013; Carranza, 2012; Araújo, 2018). A finalidade de correção de sorriso é trazer um formato mais harmônico e fisiológico, visando melhorar a aparência da gengiva. Os casos clínicos frequentes são por estética ou por indicações como eliminar as margens espessas, remoção de bolsas supra ósseas e de crescimento gengival (Carvalho 2013; Carranza, 2012; Araújo, 2018).

A gengivoplastia é um procedimento cirúrgico que normaliza a gengiva corrigindo suas deformidades, fazendo o restabelecimento dos sulcos interdentais e o remodelamento das papilas interdentais. É uma indicação onde deve existir ausência de doença periodontal e assim, podendo elaborar um contorno gengival mais harmônico (Cerroni, 2018). Em contrapartida, a gengivectomia tem como objetivo a remoção da bolsa periodontal pela exérese da parede do tecido mole da bolsa. Vale ressaltar, que a gengivectomia é indicada apenas quando há hiperplasia gengival (Grant et al., 1979).

As desvantagens da realização da gengivectomia ou da gengivoplastia envolvem o controle insatisfatório do biofilme no pós-operatório, a presença do processo inflamatório, riscos de exposições da furca nos dentes multirradiculares e a possível proporção desfavorável da coroa e raiz (Todescan, 1996). Já na parte estética, a gengivoplastia quando mal planejada pode ter sérias complicações pós-operatórias como as coroas clínicas desiguais, prolongamento extremo das coroas, alterações fonéticas e abertura de frestas interproximais, com perda da papila gengival. Diante disso, as técnicas devem ser bem indicadas após a avaliação geral do paciente bem como o cirurgião-dentista deve planejar o procedimento de forma correta (Morley \& Eubank, 2001).

Portanto, o objetivo desta revisão de literatura é relacionar as cirurgias periodontais para aumento de coroa clínica, descrevendo a história, conceito, diagnóstico o e tratamento, além cada técnica empregada atualmente, resultando e gerando conforto e bem estar ao paciente. 


\section{Metodologia}

O objetivo da pesquisa foi de caráter descritivo, propondo a identificação, registro e análise das características, fatores ou variáveis que se relacionam com o fenômeno ou processo (Perovano, 2014). Dessa forma, embasada em referências bibliográficas e científicas, relatando Óxido nítrico e o aumento do desempenho nas atividades físicas com a suplementação de origem vegetal.

Utilizou-se de um levantamento bibliográfico da literatura científica disponível em bibliotecas virtuais e sites, como as bases de dados PUBMED, LILACS, Google Scholar e SCIELO. Tomou-se como base as seguintes etapas: definição do tema, busca e seleção dos artigos, seleção das informações a serem extraídas, interpretação dos resultados e, por fim, síntese do conhecimento.

Foram analisados artigos acadêmicos, publicações de revistas acadêmicas, diretrizes, livros, utilizados como forma de estudo, de pesquisa, de revisão integrativa para um projeto conciso mais completo.

\section{Resultados e Discussão}

Segundo a literatura, em 1979 foi definida a gengivectomia, como uma excisão de tecido mole da bolsa periodontal patológica. Widmam (1918) também chamou de "retalho original de widmam" onde para estabelecer uma nova fisiologia para o osso alveolar, o autor descreveu a técnica de retalho para eliminar a bolsa periodontal. Kronfeld (1935) concluiu que na gengivectomia não poderia expor o tecido ósseo, sendo esse procedimento indicado para remover o tecido gengival hiperplásico, podendo também remover a gengiva inserida, marginal e papilar (Penteado, 2015). A técnica mais atual da gengivectomia foi concluída em 1946 por Goldman onde o preparo inicial foi aceito hoje. Com base nessas técnicas, os resultados clínicos foram favoráveis e se tornaram universalmente utilizados na odontologia (Duarte \& Castro 2004). Então surgiu a ideia de que nenhuma técnica cirúrgica deveria ser feita antes que os fatores locais estivessem controlados (Duarte \& Castro, 2004). O autor ainda afirma que, a raspagem, higiene bucal, pequenos movimentos ortodônticos, desgastes seletivos e alisamento radicular ainda é usada atualmente com o intuito de reduzir a inflamação gengival para amenizar o sangramento na execução da técnica. Atualmente, para fazer a cirurgia de aumento de coroa clínica podem ser escolhidas duas técnicas, sendo a gengivectomia em bisel externo, feito da apical para a incisal, ou em bisel interno, feita em sentido incisal para a apical. As duas técnicas cirúrgicas envolvem cirurgia com retalho de espessura total, e independente da escolha, a cirurgia será totalmente segura (Brilhante et al., 2014).

\subsection{Diagnóstico}

Para um excelente diagnóstico, deverá ser feita uma avaliação adequada ao tecido esqueléticos e moles, estruturas dentárias, tecido gengival e lábios. O sorriso gengival é causado de variáveis como o excesso vertical de maxila, sobre mordida, espaço Inter labial aumentado no repouso, maior habilidade muscular para elevar o lábio superior ao sorrir e sobressalência aumentada. A linha do sorriso deve ser avaliada pela posição dos lábios durante um sorriso natural e não forçado. Os critérios para examiná-los são o comprimento facial, neste caso é perceptível quando se nota que o comprimento do lábio superior está alterado ou podendo também ter ocorrido um crescimento ósseo vertical excessivo da maxila, e nota-se a exposição exagerada do tecido gengival durante o sorriso e dos dentes superiores, na maioria das vezes também quando o lábio está em repouso; altura do lábio superior, a sua medição deverá ser feita com paciente em repouso, e realizada ao nível da linha média. A diferença do comprimento entre o paciente do sexo masculino e feminino é mínima. É válido ressaltar, que o crescimento esquelético vertical apesar de estar completo, o lábio superior pode continuar aumentando de tamanho; a exposição dentária em repouso, quando a análise é feita por meio de uma sondagem periodontal que poderá ser afirmada, e também através de radiografias periapicais. Se o comprimento do dente estiver reduzido poderá ter presença de coroas curtas 
ou desgastes dos bordos incisais, ou se o comprimento estiver normal o mais esperado é que estejamos perante o aumento do volume gengival (Seixas et al., 2011; Panossian et al., 2010).

\subsection{Aumento No Volume Da Gengiva Causado Por Placa Bacteriana}

A presença de placa bacteriana é o principal responsável pelas alterações nos tecidos periodontais, ao diagnosticar a bactéria no tecido periodontal há uma resposta imune por parte do hospedeiro, consequentemente, tem uma reação inflamatória na gengiva e devido a não eliminação da bactéria acaba levando um aumento do volume gengival - gengivite MISHRA et al. (2011). A hiperplasia gengival é um aumento de coroa e por consequência acaba se transformando em um edema cujo a origem é de placa bacteriana (Branco, 2010).

\subsection{Aumento No Volume Da Gengiva Causado Por Fármacos}

Alguns fármacos quando são usados tanto local quanto sistemicamente causam alterações nos tecidos periodontais e uma delas é efetivamente o aumento do volume gengival resultando em uma exposição exagerada cobrindo completamente ou parcialmente os dentes (Mishra et al., 2011). Segundo a literatura, existem diversos fármacos que causam esses efeitos, são aqueles usados no tratamento da epilepsia, imunossupressores e os antagonistas dos canais de cálcio. Manifestando-se em grupos jovens entre o primeiro e o terceiro mês do tratamento farmacológico (Lindhe et al., 2003; Branco, 2010).

\subsection{Aumento No Volume Da Gengiva Causado Por Aparelho Ortodônticos}

Os aparelhos ortodônticos são considerados um dos principais fatores para a doença periodontal, visto que pode atrapalhar a higiene bucal resultando um aumento de bactérias. Os fios ortodônticos, contenções, braquetes e bandas criam volumosos sítios de placas, podendo aumentar o risco de inflamações no tecido gengival (Gkantidis et al., 2010). A hiperplasia gengival inflamatória é consequência comum do tratamento ortodôntico, a dificuldade de higienização acaba aumentando a gengiva e deixando acumular biofilme em torno do aparelho, resultando em uma inflamação crônica. Ao observar a gengiva, percebe-se uma coloração vermelha arroxeada, edematosa, podendo ter sangramento espontâneo e frouxa (Maia et al., 2011).

\subsection{Aumento No Volume Da Gengiva Causado Por Diabetes Melito}

A diabetes melito é uma doença crônica, podendo ser caracterizada por deficiência parcial ou total. A doença periodontal é umas das complicações orais mais comum, porém, a sexta mais complicada e quando não tratada, piora no controle metabólico. Uma das primeiras alterações são as perdas de inserções do tecido periodontal, com a superfície dental livre do epitélio, ocorre o acúmulo de placa e assim surgindo a bolsa gengival (Alves et al., 2007).

\subsection{Aumento No Volume Da Gengiva Causado Por Genética}

A Fibromatose Gengival Hereditária (FGH) é caracterizada pelo aumento do volume gengival excessivo, evidenciando gengiva marginal, papilas interdentais e gengiva inserida. É uma doença rara em que há uma propensão genética em alguns pacientes, enquanto em outros, não há ligações genética. Podendo aparecer como um achado isolado ou com várias sindromes hereditárias. Ocorre na infância e na juventude. Na maioria das vezes, está relacionada com a erupção dos dentes permanentes e decíduos sendo capaz de provocar falha, ou até mesmo atraso na erupção dos mesmos (Carranza \& Newman $e t$ al., 1987; Regezzi \& Sciubba, 1991; Neville et al., 1998; Scully et al., 1996; Lindhe et al., 1999; Wilson \& Kornman, 2001). 


\subsection{Tratamentos}

\subsubsection{Gengivectomia - Técnica Cirúrgica}

Segundo Pedron et al., (2010), a gengivectomia é considerada uma cirurgia de fácil execução e minimamente invasiva. Para sua execução, é preciso que o paciente não apresente defeito ósseo e tenha a presença de uma extensa faixa de gengiva queratinizada, além da cooperação na higiene oral.

Portocarrero e Barbosa (2018) realizaram uma gengivectomia para correção de sorriso gengival, usando a técnica cirúrgica convencional. Iniciou-se com afastador labial, anestesia local infiltrava. Em seguida, com uma sonda milimetrada de Williams, foram marcados os pontos sangrastes para delimitar a área a ser trabalhada e auxiliando assim na primeira incisão em bisel externo usando a lâmina de bisturi n15. Com auxílio do gengivótomo de Kirkland, foi realizada a incisão secundária para facilitar o deslocamento do tecido gengival, e com ajuda de uma cureta de McCall 13-14, removeu-se o excesso de tecido gengival, raspando os dentes e usando o cortador de cutículas para regular e refinar os bordos gengivais. Não sendo necessário a utilização de cimento cirúrgico.

A realização da gengivectomia também pode ser realizada com o auxílio do laser tipo $\mathrm{CO}^{2}$, sendo um procedimento de curta duração e de fácil execução. Ele resulta em um efeito imediato e satisfatório, quando comparado a uma gengivectomia convencional, produzindo um excelente hemostático, melhorando a visualização e causando um mínimo desconforto pósoperatório para o paciente (Fornaini \& Rocca, 2012). Na realização da cirurgia de gengivectomia usando laser Light Touch, usando anestesia local infiltrativa, o nível do osso é localizado com uma sonda periodontal, e a gengiva que será ser removida é mercada. Posteriormente, a redução da gengiva é feita com o Light Touch, e na mesma superfície de onde foi usado o laser, utilizou-se o mesmo em energia de impulso inferior para realizar o alisamento. (Onisor et al., 2013).

Duarte et al., (2019) realizaram uma gengivectomia associada a osteotomia minimamente invasiva para correção de sorriso gengival. Iniciou-se com a anestesia infiltrada utilizando a articaína como anestésico de escolha, marcando os pontos sangrantes com auxílio da sonda periodontal de Willians nas regiões onde seria feito a incisãoparamarginal e incisão intrasulcularcom bisturi 15c. Ao realizar a remoção do tecido gengival, foi feita uma avaliação da junção cemento-esmalte e crista-óssea alveolar utilizando a sonda de Who. Após a realização da gengivectomia, foi feita a osteotomia utilizando a técnica de Flapless, e avaliando novamente a crista-óssea durante e após a osteotomia, e por fim, realizou-se a remoção dos fragmentos ósseos, raspagem e alisamento radicular. A técnica utilizada é imprescindível para um sorriso gengival estético e harmônico, somando-se a recuperação e pós-cirúrgico almejado.

A realização da cirurgia sem osteotomia possivelmente acarretará em um novo aumento de tecido gengival durante o processo de recuperação. Estudos apontam que há possibilidade de um crescimento da gengiva após 6 meses de realização da mesma, sem a remoção de tecido ósseo (Pontes et al. 2016).

\subsection{Gengivoplastia - Técnica Cirúrgica}

Para a indicação da gengivoplastia, tem-se papilas interdentais, redução de margens gengivais espessas, hiperplasia devido às condições hormonais, congênitas e medicamentos. A cirurgia de gengivoplastia tem por objetivo criar ou devolver um contorno gengival harmônico (Silva et al. 2010).

A cirurgia de gengivoplastia foi utilizada com a finalidade de resolução estética. Tem por início a antissepsia intra e extra-oral, anestesia por bloqueio dos nervos e complementação com a técnica infiltrava. A sondagem é realizada para identificar a quantidade de tecido gengival a ser removido e feita a demarcação dos pontos sangrantes. A incisão pode realizada com bisturi (lâmina ${ }^{\circ} 15 \mathrm{c}$ ) e gengivótomo de Kirkland. A incisão é feita com angulação em $45^{\circ}$ de bisel interno com propósito de obter uma margem festonada e afilada da gengiva remanescente. Posteriormente, na incisão secundária, o tecido gengival interproximal foi separado utilizando o gengivótomo de Orban eostecidos incisados foram removidos cuidadosamente 
com o auxílio das curetas de Gracey. Foi realizado um retalho de espessura total utilizando descolado de Molt 2-4, com a finalidade de identificar o tecido ósseo e cogitar uma possível necessidade de osteotomia/osteoplastia, porém, observou-se que não havia necessidade de desgaste ósseo. Contudo, foi realizada uma sutura com fio de nylon 5-0, colocando a margem gengival no local desejado (Nascimento et al., 2016).

De acordo com Oliveira (2018), na execução da técnica cirúrgica, é possível produzir uma incisão com bisturi convencional ou optar pelo eletro cirurgia. Embora o primeiro seja o mais utilizado, ambas alcançam o mesmo resultado estético e satisfatório, por isso, a escolha deve ser realizada durante o plano de tratamento e em consenso com o paciente para cada caso específico. A autora ainda realiza uma cirurgia de gengivoplastia utilizando o bisturi eletrônico com finalidade estética. Iniciou-se anestesiando e bloqueando o nervo alveolar superior anterior e do nervo nasopalatino, utilizando o anestésico de escolha, contendo Lidocaína 2\% com epinefrina 1:100.000, posteriormente, foi colocado um guia cirúrgico na posição adequada e com bisturi Bard Parker, acompanhado da lâmina n ${ }^{\circ} 15$, que foi delineado o contorno gengival. Em seguida, foi usado um bisturi eletrônico EMAI de ponta capilar para excisão da margem gengival. Para finalizar, foi usado o gengivótomo de Kirkland para escarificação da área para obter afilamento da nova margem gengival. Ao final da cirurgia, foi utilizado cimento cirúrgico como forma de proteção.

Pedron \& Silva (2017), relataram um procedimento cirúrgico ressectivo de gengivoplastia e aplicação de toxina botulínica para correção de sorriso gengival. Foi iniciado com a anestesia infiltrava, em seguida, foram marcados os pontos sangrantes com auxílio da sonda milimetrada, unindo os pontos com bisturi elétrico. Posteriormente, foi realizado o scraping, uma técnica semelhante à de bisel externo com o propósito de separar o tecido. Não houve necessidade de cimento cirúrgico. Após 15 dias de cirurgia, foi observado reparação tecidual satisfatória. Todavia, houve a persistência do sorriso gengival, diante disso, foi realizada a aplicação de toxina botulínica. A superfície da pele foi desinfetada com etanol evitando a infecção do local e removendo a oleosidade da mesma. Em seguida, foi aplicado anestésico local com a intenção de promover conforto durante o procedimento. A toxina botulínica tipo A foi diluída em $1,7 \mathrm{ml}$ de solução salina, injetando 2 unidade no sítio preconizado lateralmente a cada narina. Após a aplicação, a orientação passada é não baixar a cabeça nas primeiras 4 horas e não realizar atividades físicas por 24 horas.

\subsection{Discussão}

Segundo Pedron (2016), quando há exposição gengival acima de 3mm, é caracterizada uma condição não estética, afetando diretamente o psicológico de alguns pacientes. Atenções devem ser tomadas ao realizar uma avaliação intra-oral e extraoral, levando-se em consideração as condições como altura e largura tanto da coroa do elemento quanto do rosto do paciente, (Sharma et al., 2012). Somado a isso, outra forma importante para uma avaliação é o exame radiográfico e a análise diagnóstica, sendo de fundamental importância para uma reabilitação bem sucedida. O plano de tratamento e um diagnóstico inadequado, podem gerar resultados insatisfatórios, porém quando bem avaliados, é alcançado um pré-requisito para uma terapia de sucesso (Jorgensen \& Nowzari, 2001).

Segundo Pedron et al. (2010), a gengivectomia e a gengivoplastia são indicadas quando incluem a eliminação de hiperplasia gengival, preparos subgengivais, pacientes com linha do sorriso alta, região anteroposterior com indicações estéticas e erupção passiva alterada. $\mathrm{O}$ autor ainda ressalta que há situações onde são contraindicadas para a realização da cirurgia de gengivectomia, que seriam controle inadequado de biofilme, criação de desnível marginal, processo inflamatório, região de furca, desproporções entre raiz e coroa e estreita faixa de gengiva queratinizada. Entretanto, na técnica de gengivoplastia, a principal contraindicação são os casos em que provocariam exposição excessiva de tecido conjuntivo (Duarte et al., 2009). 
Existem vários fatores que podem levar a um diagnóstico de aumento de coroa clínica, entre eles, tem-se o fator induzido por placa bacteriana, onde seu principal sinal é o aumento, inflamação e alterações nos tecidos periodontais (BRANCO, 2010). Porém, o aumento gengival quando é diagnosticado através de fármacos, podem modificar a resposta imunológica e inflamatória dos tecidos periodontais, (Tunes \& RAPP, 1999). Outro fator que leva o aumento gengival, é o uso do aparelho ortodôntico, onde a falta de escovação se torna deficiente, pois há impedimentos que dificultam a realização da escovação, como por exemplo, a presença de bandas, braquetes e contenções, (Maia et al., 2011; Braga et al., 2014; Brito et al., 2016; Cardia et al., 2016). Com relação à Diabetes Melito associado ao aumento gengival, uma vez que um paciente é diagnosticado, fatores como a glicemia, e anormalidade do hospedeiro diante das infecções bucais são os responsáveis pelo maior predomínio desta complicação em diabéticos quando comparado aos não diabéticos (Magini \& Schiochett, 2000). Todavia, o aumento gengival também é acometido geneticamente, a doença é conhecida como Fibroma tose Gengival Hereditária (FGH). É uma doença que afeta uma em cada 750.000 pessoas (Canavarros et al., 2001). A FGH tem um crescimento lento, difuso, progressivo e benigno dos tecidos gengivais que resulta no recobrimento parcial ou total dos dentes pela gengiva hiperplásica queratinizada, ocorrendo graves transtornos estéticos para o paciente que é acometido por tal condição (Valente et al., 2004).

Segundo Silberg et al. (2009) as diferentes formas de tratamento variam de acordo com o biotipo gengival do paciente. A escolha da técnica depende diretamente da faixa de gengiva inserida e da precisão ou não de cirurgia óssea (Deas et al., 2014).

A cirurgia de gengivectomia para correção de sorriso gengival usando a técnica convencional, usualmente resulta em satisfação total dos pacientes de $5 \mathrm{~mm}$ de profundidade de sondagem. Nota-se a diferença e a melhora imediata na harmonia do sorriso, onde apresenta-se mais estético, ganha proporção e tamanho ideal. (Portocarrero \& Barbosa, 2018).

Fornaini e Rocca, (2012) realizaram uma cirurgia de hiperplasia gengival causado por fármaco, usando técnica de gengivectomia associada a laser $\mathrm{C} 0^{2}$ como escolha para realização do procedimento. Após 3 semanas, foi notado que nesse decurso, houve uma completa renovação e não foi observada nenhuma intercorrência nos meses subsequentes. Todavia, os autores puderam concluir que o laser tem poder de tratar condições em pacientes com problemas de saúde generalizados, trazendo um maior conforto e sucesso nos procedimentos. Entretanto, (Aboujaoude et al., 2016) realizaram uma comparação com laser Diodo e bisturi convencional no tratamento da hiperplasia gengival hereditária, usando a técnica de gengivectomia. Os autores chegaram à conclusão que o laser Diodo mostrou excelente visibilidade durante a cirurgia devido as suas propriedades hemostáticas, na qual provocou um bom recontorno gengival. No entanto, o procedimento utilizando o bisturi foi mais rápido, o que diminuiu o tempo de procedimento. Por fim, as duas técnicas mostraram-se satisfatórias, ressaltando o alto custo do laser face ao bisturi.

Pires et al., (2010) realizou um procedimento plástico periodontal em paciente com sorriso gengival, usando a técnica de gengivectomia associada a osteotomia e osteoplastia. A cirurgia foi um grande sucesso, onde puderam acompanhar um controle pós-operatório a cada 7, 30 e 60 dias, quando pode-se observar uma recuperação da harmonia entre os lábios, dentes e gengivas com aspectos de saúde periodontal presente (características de "casca de laranja", cor rosa pálido e ameias preenchidas integralmente pelas papilas). Os autores concluíram que em 2 meses de pós-operatório, podem ser definidos como um tempo satisfatório para melhor visualização dos resultados finais.

Nascimento et al., (2016) usaram a técnica de gengivoplastia para resolução estética de sorriso gengival. Foi usando a técnica de bisturi convencional na incisão primária, um guia cirúrgico para auxiliar na incisão secundária, retalho de espessura total para exposição de tecido ósseo e osteotomia para o restabelecimento do espaço biológico. Após 7 dias de pós-operatório, foi observado uma grande evolução e redução do sorriso gengival. Em 1 ano de acompanhamento, foi alcançado saúde periodontal e satisfação, sem sinais de recidiva. Porém, (Domínguez-Diaz \& Lopéz-Flores 2020) também realizaram a técnica 
de cirurgia convencional sem a osteotomia e obtiveram ótimos resultados, sem complicações após 7 dias da cirurgia com satisfação do paciente.

Vasconcelos et al., (2003) relatam que o bisturi elétrico na sua principal vantagem, quando relacionado ao bisturi convencional, é sua rapidez ao realizar os procedimentos. (Oliveira, 2018), realizou uma cirurgia com a necessidade de promover otimização da estética gengival onde as áreas apresentavam pigmentações e após a cirurgia, obteve uma nova margem gengival trazendo conforto à paciente. Entretanto, notou-se que os eletrodos oferecem um melhor acesso nas regiões mais delicadas quando se trata do contorno gengival, cujo a localização mostra dificuldades quando comparados a prática de incisão como bisturi frio. A autora concluiu que após 90 dias que a cirurgia foi realizada, observaram uma adequada estabilidade dos tecidos e aspectos periodontais normais.

Pedron e Silva (2017), realizaram um procedimento cirúrgico de gengivoplastia com aplicação de toxina botulínica, com 7 dias de consulta e orientação de higiene bucal. A cirurgia foi realizada com o auxílio do bisturi elétrico para separação dos tecidos. Após 15 dias sem queixa, puderam observar reparação dos tecidos satisfatórios e foi realizada a aplicação da toxina botulínica tipo A. Em 10 dias, foi realizada uma avaliação e apresentou deiscência uniforme no lábio superior onde foi feito a aplicação da toxina botulínica. Não houve efeitos colaterais e queixas. (Moura et al., 2017) reuniram pessoas do sexo feminino com objetivo de corrigir seus sorrisos antiestético e foi possível realizar uma cirurgia convencional sem osteotomia associada a toxina botulínica e o resultado mostrou positivo com o uso da toxina botulínica tipo A, uma técnica segura e eficaz no tratamento.

Diante do estudo, foram observados diferentes resultados de cada um dos autores quanto as suas técnicas. (Portocarrero \& Barbosa, 2018) usaram a técnica tradicional em gengivectomia e em 14 dias chegaram a um objetivo satisfatório. Porém, quando é usado laser, na reparação tecidual, traz uma alta produção de colágeno, e uma melhora na remodelação dos tecidos conjuntivos e seus resultados surgem após 3 semanas (Amorim et al., 2006; Fornaini \& Rocca, 2012). $\mathrm{Na}$ cirurgia de gengivectomia com osteotomia é observado uma rápida melhora no pós-operatório e seu resultado finalse dá em 2 meses (Pires et al., 2010). Todavia, (Domínguez-Diaz \& Lopéz-Flores 2020) realizou também uma cirurgia tradicional onde mostrou um resultado em 7 dias com satisfação total e sem complicações. Quanto ao uso do bisturi eletrônico, mostrou-se seguro, adequado e viável, com sua capacidade de corte minimamente invasivo, redução no tempo de procedimento e proporciona um pós-operatório confortável para cada um dos pacientes (Oliveira, 2018). Contudo, (Brito et al., 2016; Moura et al., 2017; Pedron 2016) fizeram uma análise da cirurgia associada ao uso de cirurgia convencional sem osteotomia associada a toxina botulínica tipo A e encontraram resultados clínicos no aumento do vermelho no sorriso, em comparação aos pacientes que usaram técnicas tradicionais alcançando um resultado clínico positivo.

\section{Considerações Finais}

Conclui-se que diante do exposto, a gengivoplastia é similar a gengivectomia, porém, com diferenças que na primeira citada, o objetivo seria que a gengiva se torne mais estética na ausência de patologias, já na gengivectomia, seria para excisão da gengiva com a patologia. As cirurgias plásticas periodontais estão a disposição para corretas técnicas clínicas e restituição do sorriso harmônico dos nossos pacientes.

\section{Referências}

Aboujaoude, S., Cassia, A., \& Moukarzel, C. (2016). Diode Laser Versus Scalpel in the Treatment of Hereditary Gingival Fibromatosis in a 6-Year-Old Boy. Clin Pract, 6(4):895.

Alves, C., Andion, J., Brandão, M., \& Menezes, R. (2007). Mecanismo Patogênicos da Doença Periodontal Associada ao Diabetes Melito. Scielo Brasil. Salvador. 
Amorim, J. C. F., Sousa; G. R., Silveira, L. B., Prates, R. A., Pinotti, M., \& Ribeiro, M. S. (2006). Clinical Study of the Gingiva Healing after Gingivectomy and Low-Level Laser Therapy. Photomedicine and Laser Surgery, 24(5), 588-594.

Araújo, A. K. C., \& Barros, T. K. M. (2018). Sorriso gengival: etiologia, diagnóstico e tratamento por intermédio de gengivectomia e gengivoplastia. Porto Velho, RO, 23p. Trabalho de Conclusão de Curso, (Curso de Odontologia). Centro Universitário São Lucas.

Black, G. V. (1915). A work on special dental pathology devoted to the diseases and treatment of the investig tissues of the teeth and dental pulp. Chicago: Medico-Dental Publishing company; 489.

Box, H. K. (1928). Treatment of the periodontal pocket. Toronto: The University of Toronto Press, 123.

Braga, M. S., Nascimento, J. M. Q., Camargo, E. B., Veloso Filho, J. M. S. C, Falcão, E. P., \& Zuza, E. P. (2014). Cirurgia plástica periodontal para correção de erupção passiva alterada. Braz J Periodontol., 24(4), 64-68.

Branco, L. P. C. (2010). Aumento de Volume Gengival induzido por Fármacos. Porto. Dissertação [Mestrado em Medicina Dentária] - Faculdade de Medicina Dentária da Universidade do Porto.

Brilhante, F. V. (2014). Cirurgia periodontal estética em dentes anteriores. In: Full dentistry in Science. 39-44.

Brito, E. C. D., Alves, W. A., Souza, J. N. L., Rodrigues, R. Q. F., \& Souza, M. M. L. (2016). Gengivectomia/gengivoplastia associada à toxina botulínica para correção de sorriso gengival. Braz J Periodontol.26(3), 50-56.

Canavarros, V. P., Martinelli, C. P., \& Chiconelli, G. M. (2001). Fibromatose gengival hereditária: Identificação, tratamento e controle. Revista Brasileira de Cirurgia e Implantodontia, 8(29), 71-74.

Cardia, G. S., Tormena, M., Tolentino, E. S., Pinto, G. N. S., \& Tolentino, L. S. (2016). Planejamento integrado periodontal e restaurador - relato de caso clínico. Braz J Periodontol., 26(2), 48-52.

Carranza, A. F., Newman, M. G., Takei, H. H., \& Klokkevold, R. P. (2012). Técnicas Cirúrgicas Gengivais.cap.56. Carranza, A. F. Carranza: Periodontia Clínica.11 $11^{\mathrm{a}}$.Ed. Rio de Janeiro: Elsevier, p. 682-688, tiragem $3^{\mathrm{a}}, 1164$.

Carranza, F. A., \& Newman, M. G. (1997). Periodontia Clínica. 8a . ed. São Paulo: Guanabara Koogan.

Carvalho, E. P., \& Macedo, G. O. (2013). Harmonização do sorriso através do recontorno gengival associado à remodelação cosmética: relato de caso. Aracaju, SE, 8. Trabalho De Conclusão de Curso, (Odontologia). Universidades Tiradentes.

Cerroni, S., Pasquantonio, G., Condomínio, R., \& Loredana, C. L. (2018). Aparelho fixo ortodôntico e status periodontal: uma revisão sistemática atualizada. The OpenDentistry Jornal.,12(1), 614-622.

Cirino, C. C. S. Resolução estética de sorriso gengival através da técnica de gengivoplastia: relato de caso. Brazilian Journal of Surgery and Clinical.

Oliveira, D. N., Souza, L. Q. R., et al. (2019). Gengivectomia com osteotomia minimamente traumática. Archives Of Health Investigation, [S. l.], 7, https://www.archhealthinvestigation.com.br/ArcHI/article/view/3977.

Deas, D. E. (2014). Crown lenghtening in the maxillary anterior region: a 6-month prospective clinical study. In: International Journal of Periodontics and Restorative Dentistry. 34, 365-373.

Do Nascimento, B. de F. K. S.; et al., Cirurgia Plástica Periodontal: Gengivectomia e Gengivoplastia: Relato de Caso Clínico. 2(2) 1-13.

Dominguez-Diaz, D. D., \& Lopez-Flores, E. U. (2020). Tratamiento multidisciplinarario mínimomente invasivo de la sonrisa gengival . RevCient Odontol (Lima), 8 (2): e022.

Duarte, C. A., \& Castro, M. V. M. Alterações periodontais estéticas. In: Duarte, C. A.; Castro, M. V. M. Cirurgia estética periodontal. São Paulo: Santos, 2004. cap.3. p.17-22.

Duarte, C. A.; Pereira C. A; \& Castro M. V. M. Retalho Mucoperiosteal. In: Duarte, C. A. Cirurgia periodontal: pré-protética, estética e peri-implantar. (3a ed.), Santos, 2009.

Dutra, M. B., Ritter de Borgatto, A., Derech, C. D., \& Rocha R. (2011). Influência da exposição gengival na estética do sorriso. Dental press J. Orthod.

Faria, G J et al. A importância do planejamento multidiscipilinar para correção do sorriso gengival: Relato de caso clínico. http://dx. doi. org/10.15600/22381236/fol. v25n1p61-65. Revista da Faculdade de Odontologia de Lins, 25(1), 61-66, 2015.

Fornaini, C., \& Rocca, J. P. (2012). Co2 Laser Treatment of Drug-Induced Gingival Overgrowth - Case Report. Laser Therapy, $21,39-42$.

GengivalRessectivanaEstéticaDentogengivofacial. Rev. Odontol. Bras. Central. S57-60. 2017.

Gkantidis, N., Christou P., \& Topouzelis, E. N. (2010). The orthondonticperiodontic interrelationship in integrate dtreatmente challenges: a systematic review. J Oral Rehabil., 37(3), 77-9.

Goldman, H. M. (1946). Gingivectomy: Indications, contraindications, and method. American journal of orthodontics and oral surgery, 32, A323-A326.

Goldman, H. M. (1950). The development of physiologic gingival contours by gingivoplasty. Oral Surgery, Oral Medicine, Oral Pathology, 3, 879-888

Gottlieb, B. (1928). The formation of the periodontal pocket: diffuse atrophy of alveolar bone. J Am Dent Assoc. 15, 462-76 
Grant, D. A., Stem, I. B.; \& Everett, F. G. (1979). Gengivectomy and gengivoplasty.In: Periodontics: a concept-theoryandpractice. $4^{a}$ ed. St Louis: C.V. Mosby.

Jorgensen, M., \& Nowzari, E. (2001). Aesthetic crown lengthening. Periodontology, 27 ,45-58.

Kronfeld, R. (1935). The Condition of the alveolar bone underlying periodontal pockets. J Periodontol. 1935; 6,22-9.

Lindhe, J., Karring, T., \& Lang, N.P. (2003). Clinical Periodontology and Implant Dentistry. (4a ed.), Editora: Blackwell Munksgaard.

Lindhe, J., Karring, T., \& Lang, N.P. (1999). Tratado dePeriodontia Clínica e ImplantologiaOral. (3a ed.), Guanabara Koogan.

Lipska, W., Lipski, M., Lisiewicz, M., Gala, A., Gronkiewicz, K., Darczuk, D., \& Chomyszyn-Gajewska, M. (2015). Clinical crown lengthening - a case report. Folia Medica Cracoviensia, 55, 25-35.

Lisboa, A H., Gomes, J. C., Jorge, J. H., Bombarda, N. H. C. (2011). Gengivectomia e gengivoplastia: relato de caso clínico. Full dent. sci, 1(4), $402-405$.

Magini, R. S., \& Schiochett, C. (2000). Cicloporina: um fármaco indutor de crescimento gengival. Revista Brasileira de Odontologia, 57(6), 376-379.

Maia, L. P., Novais Jr, A. B., Sousa, S. L. C., Palioto, D. B., Taba Jr., \& M., Grisi, M. F. M. (2011). Ortodontia e periodontia - parte I: alterações periodontais apósa instalação de aparelho ortodôntico. Braz J Periodontol., 21(3), 40- 45.

Michael, G. J., \& Hessam, N. (2001). Aestheticcrownlengthening. Periodontology, v27, 45-58.

Mishra, M. B., Khan Z. Y., Mishra S. (2011). Gingival Overgrowth and Drug Association: A review. Ind J Med Scienc.

Moritz, A., Gutknecht, N., Doertbudak, O., Goharkhay, K., Schoop, U., Schauer, P., \& Sperr, W, (1997). Bacterial Reduction in Periodontal Pockets Through Irradiation with a Diode Laser: A Pilot Study. Journal of Clinical Laser Medicine \& Surgery, 15(1), 33-37.

Morley, J., \& Eubank, J. (2001). Elementos macroestéticos da análise do sorriso. JADABrasil, 4, 7-12.

Moura, L. A, Vasconcelos, R. S. N, Correa, A. O. N, Vasconcelos, L. K. M. F., \& Moura, R. R. (2017). Associação de técnica cirúrgica e toxina botulínica para correção de sorriso gengival. ImplantNewsPerio , 2(3): 515-520.

Nascimento, B. F. K. S., Silva, C. A., Corrêa, T. A., Andrade, T. M., Duarte, Y. F., \& Cirino, C. C. S. (2016). ResoluçãoEstética de SorrisoGengivalAtravés da Técnica de Gengivoplastia: Relato de Caso. Brazilian Journal of Surgery and Clinical Research - BJSCR. Belém, 14(3).

Neville, B. W., Damm, D. D., \& Allen, C. M. (1998). Patologiaoral e maxilofacial.: GuanabaraKoogan.

Oliveira, D. B. (2018). Uso do bisturi eletrônico em gengivoplastia: relato de caso clínico. 2018. 21 f. Trabalho de Conclusão de Curso (Graduação em Odontologia) - Universidade Federal de Uberlândia, Uberlândia..

Onisor, I., et al. (2013). Cutting and coagulation during intraoral soft tissue surgery using Er:YAG laser. Eur J Paediatr Dent, Carimate, 14(2), 140-145.

Ottoni, J., \& Magalhães, L. F. (2006). Cirurgia plástica periodontal e periimplantar: beleza com proporção e harmonia. Artes Médicas.

Panossian, A. J., \& Block, M. S. (2010). Evoliation of the Smile: Facial and Dental Considerations. Journal Oral Maxillofac. Surgery, 68, 547-554.

Pedron, I. G. (2016). Harmonização da Estética Dentogengivofacial. Clínica - International Journal of Brazilian Dentistry, Florianópolis, 12(2), 150-155.

Pedron, I. G., Silva, L. P. N. Aplicação da ToxinaBotulínicaAssociada à cirurgia.

Pedron, I. G., Utumi, R. E., Tancrede, A. C. R., Parrella, A., \& Perez, F. G. E. (2010). Sorriso Gengival: Cirurgia Ressectiva Coadjuvante à Estética Dental. São Paulo. Odonto, 88

Penteado, Luiz Alexandre Moura. (2015). Gengivectomia e Gengivoplastia na Estética doSorriso-Relato de caso. Revista Incelências, 5(1).

Pickerill, H. P. (1912). Stomatology in general practice. London: Frowde, Hodder and Stoughton. 308.

Pires, C. V, Souza, C. G. L. G., \& Menezes, S. A. F. (2010). Procedimentos Plásticos Periodontais Em Paciente Com Sorriso Gengival - Relato De Caso. R. Periodontia. 20(1).

Pontes, S. A., Duarte, P. M., Oliveira, A. C. G., Coelho, E. F., Esteves, F. M., Mello, G. B. R., Tenorio, I. P., et al. (2016). Aumento de coroa clínica estético minimamente invasivo: relato de caso de 12 meses. Revista Saúde-UNG-Ser, 10(3-4), 55-64.

Portocarrero, H. S. D. (2018). Correção de sorriso gengival através da técnica de gengivectomia: relato de caso. Orientador: Ricardo dos Santos Barbosa. 6f. Trabalho de Conclusão de Curso (Bacharel em Odontologia) - Centro Universitário do Planalto Central Apparecido dos Santos.

Regezzi, J.A., \& Sciubba, J.J. (2016). Patologia bucal. Correlações clinicopatológicas. 1. ed. Rio de Janeiro:Research - BJSCR, 14(3), 65-69.

Rosemberg, E. S., Cho, S. C., \& Garber, D. A. (1999). Crown lenghtening revisited. In: Compendium of continuing education in dentistry, $20,527-532$.

Scully, C., Flint, S. R., \& Porter, S. R. (1996). Atlas colorido de doenças da boca. Diagnóstico e tratamento. 2a . ed. Rio de Janeiro: Revinter.

Seixas, M. R., Costa-Pinto, R. A., \& Araújo, T. M. (2011). Checklist dos aspectos estéticos a serem considerados no diagnóstico e tratamento do sorriso gengival. Dental Press Journal of Orthodontics, 16(2), 131-157. 
Research, Society and Development, v. 10, n. 16, e397101624227, 2021

(CC BY 4.0) | ISSN 2525-3409 | DOI: http://dx.doi.org/10.33448/rsd-v10i16.24227

Sharma, A., Rahul, G.R., Poduval, S. T., \& Shetty, K. (2012). Short clinical crowns (SCC) - treatment considerations and techniques. Journal of Clinical and Experimental Dentistry, 4(4), 230-236.

Silberg, N., Goldstein, M., \& Smidt, A. (2009). Excessive gingival display - etiology, diagnosis, and treatment modalities. In: Quintessence International. 40, 809-818.

Silva, D. B., Zaffalon, G. T., Corazza, P. F. L., Bacci J. E., Steiner-Oliveira, C., |\& Magalhãe, J. C. A. (2010). Cirurgia plástica periodontal para otimização da harmonia dentogengival - relato de caso clínico. Brazilian Journal of Health.

Silva, H. F. V., Leite, R. B., Oliveira, M. S. G., Leite, J. V. C., Felismino, C. M. O., Cruz M. E. A., Santos, A., Gusmão, G. P., \& Lima, L. N. C. (2021). Avaliação de diferentes técnicas para correção do sorriso gengival: Revisão da literatura. Research, Society and Development, 10(5).

Soares, P. B. F, Bragança, G. F, Borges, J. S., Verissimo, C., \& Soares, C. J. (2017). Estética do sorriso: Planejamento digital, cirurgia periodontal e procedimento restaurador. ImplantNewsPerio , 2(5): 895-909

Sousa, S. M. L., Araújo, I. D. T., Abrantes, P. S., Borges, B. C. D. \&Assunção, I. V. (2019). Harmonização do sorriso com gengivoplastia e resina composta. Revista Ciência Plural, 5(3), 143-152, 12.

Stern, T., Everet, F., Robicsek, K. S. (1965). A pionner in the surgical treatment of periodontal disease. J Periodontal. 36:265-8.

Todescan, R., Silva, E. E. B., \& Silva, O J. (1996). Atlas de prótese parcial removível, São Paulo: Santos.

Tunes, U. R., Rapp, G. E. (1999). Influência das condições sistêmicas sobre as doenças periodontais. Atualização em periodontia e implantodontia. São Paulo: Artes médicas, 44-46.

Valente, R. O., Pacheco, D. F., \& Robinson, W. M. (2004). Fibromatose gengival hereditária: apresentação de caso clínico e discussão dos aspectos clínicos, histológicos, genéticos e bioéticos. Revista Odonto Ciência, 19(43), 40-45.

Vasconcelos, R. F., \& Pereira, L. H. F., Santos. (2003). O uso da eletrocirurgia em procedimentos bucais. Revista de Cirurgia e Traumatologia BMF. 3(3).

Widman, L (1918). The operative treatment of pyorrhea alveolaris. A new surgical method. SvenskTandläkaretidskrift (reviwed in British Dental Journal) 1, 293.

Wilson, T. G., \& Kornman, K. S. (2001). Fundamentos de Periodontia. Quintessence. 